\title{
QUALIDADE DA FARINHA DE MANDIOCA DO GRUPO SECA ${ }^{1}$
}

\author{
Renan Campos CHISTÉ ${ }^{2}$, Kelly de Oliveira COHEN ${ }^{3, *}$, Erla de Assunção MATHIAS ${ }^{4}$, \\ Afonso Guilherme Araújo RAMOA JÚNIOR ${ }^{4}$
}

\begin{abstract}
RESUMO
Na Região Norte, a farinha de mandioca é produzida em pequenos estabelecimentos denominados de "Casas de Farinha", que apresentam problemas de adequação às exigências da legislação devido ao seu processamento e às precárias condições higiênico-sanitárias. Este trabalho teve como objetivo avaliar o padrão de qualidade da farinha de mandioca do grupo seca, subgrupo fina, tipo 1. Foram coletadas dez amostras de farinha de mandioca nos principais supermercados e feiras da cidade de Belém, PA, tendo sido realizadas análises físico-químicas, microbiológicas e pesquisa de sujidades. De acordo com a Portaria No 554 de 30.08 .1995 da Secretaria da Agricultura, do Abastecimento e Reforma Agrária, das dez amostras de farinha de mandioca analisadas, em todas foram encontrados valores acima do padrão permitido para a acidez total, cujo valor máximo é de 3 meq. NaOH/100 g, e cinco amostras apresentaram-se abaixo da tolerância mínima exigida para o amido, que é de 75\%. De acordo com a Resolução RDC n 12 de 02.01 .2001 da Agência Nacional de Vigilância Sanitária, todas as amostras de farinha de mandioca apresentaram-se dentro dos padrões aceitáveis de contaminantes microbiológicos. De acordo com a Resolução RDC n ${ }^{\circ} 175$ de 08.07.2003, das dez amostras de farinha de mandioca analisadas, foram encontradas oito fora dos padrões exigidos, por apresentarem sujidades.
\end{abstract}

Palavras-chave: manhiot esculenta, amido, microbiologia.

\section{SUMMARY}

QUALITY OF CASSAVA FLOUR FROM A DRY GROUP. In the north of Brazil, cassava flour is produced in small-scale processing units called 'flour mill houses`. These processing units have difficulty in complying with current legislation due to processing methods and to poor sanitary conditions. The objective of this study is to evaluate the quality standard of cassava flour from the dry group, subgroup "fina", type 1. Ten samples of cassava flour were collected from the main supermarkets and free markets in Belém-PA, and the physical-chemical, microbiological and dirt research analyses were carried out. According to Regulation $\mathrm{n}^{\circ} 554$ from 08/30/1995 issued by the State Agriculture Secretariat, all cassava flour samples analyzed showed total acidity values above the permitted standard ( $3 \mathrm{meq} \mathrm{NaOH} / 100 \mathrm{~g}$ ) and five samples were below the minimum tolerance level required for starch (75\%). According to Resolution RDC $n^{\circ} 12$ from 01/02/2001 of the National Sanitary Control Agency, all cassava flour samples were under the acceptable standards for microbiological contaminants. According to Resolution CNNPA $\mathrm{n}^{\circ} 12$ from 1978, eight of the analyzed samples did not comply to the permitted standards because they showed dirt.

Keywords: manhiot esculenta, starch, microbiology.

\section{1 - INTRODUÇÃO}

A mandioca se destaca como uma das principais culturas no Brasil, sendo que a maior parte da sua produção destina-se à fabricação de farinha de mandioca e o restante divide-se entre alimentação humana, animal e processamento para amido (fécula) [6].

Embora seja a forma mais ampla de aproveitamento industrial da mandioca, a farinha não é um produto muito valorizado, sobretudo pela falta de uniformidade [5]. Segundo LIMA [11], a heterogeneidade da farinha de mandioca é devido, principalmente, à fabricação por pequenos

\footnotetext{
${ }^{1}$ Recebido para publicação em 17/3/2006. Aceito para publicação em 20/10/2006 (001692)

2 Campus Universitário do Guamá, Universidade Federal do Pará, Rua Augusto Côrrea, 01, C. P. 479, CEP 66075-110,

Belém, Pará, Brasil

E-mail: renanchiste@gmail.com

${ }^{3}$ Embrapa Amazônia Oriental, Trav. Dr. Enéas Pinheiro $s / n$,

C. P. 48, CEP 66095-100, Belém (PA)

E-mail:cohen@cpatu.embrapa.br

${ }^{4}$ Departamento de Engenharia de Alimentos,

Universidade Federal do Pará, Belém (PA)

E-mails:erlamorena@yahoo.com.br,afonsoramoa@gmail.com

* A quem a correspondência deve ser enviada
}

produtores para seu próprio uso, cada um seguindo um processo próprio. Numa mesma propriedade é raro ocorrer uniformidade em fabricações sucessivas.

De acordo com CEREDA \& VILPOUX [5], além da heterogeneidade entre os fabricantes de farinha de uma mesma região, existem muitos tipos de farinha nos diversos Estados brasileiros e, muitas vezes, as classificações de qualidade são particulares a cada fabricante. Essa variabilidade dos mercados de farinha dificulta a comercialização em nível nacional por uma mesma empresa.

Na Região Norte, a farinha de mandioca comercializada é produzida em pequenos estabelecimentos denominados de “Casas de Farinha”, onde as condições higiênico-sanitárias são precárias, podendo se observar animais transitando na área de processamento e insetos, além de outras irregularidades, comprometendo a qualidade do produto e a segurança alimentar.

Além das precárias condições higiênico-sanitárias das Casas de Farinha, as diferenças em seu processamento, tais como fermentação da mandioca, adição de corantes, intensidade da prensagem da massa triturada e temperatura do forno, influenciam no padrão de qualidade das farinhas. 
Este trabalho teve como objetivo avaliar o padrão de qualidade das farinhas de mandioca do grupo seca, subgrupo fina, tipo 1, comercializadas nos principais supermercados e feiras da cidade de Belém, PA.

\section{2 - MATERIAL E MÉTODOS}

As análises físico-químicas, microbiológicas e pesquisa de sujidades foram feitas em dez amostras de farinha de mandioca do grupo seca, subgrupo fina, tipo 1, produzidas no Estado do Pará, de acordo com as metodologias citadas a seguir.

\section{1 - Caracterização físico-química}

- Teor de umidade - determinado de acordo com o método 31.1.02, da AOAC [1];

- $\quad$ Atividade de água - determinada em medidor de atividade de água portátil, modelo Pawkit, marca Decagon;

- Teor de cinzas - as amostras foram carbonizadas até cessar a liberação de fumaça e, posteriormente, calcinadas em mufla a $540{ }^{\circ} \mathrm{C}$ até peso constante, segundo o método 31.1.04, da AOAC [1];

- Teor de lipídios - obtido por extração em Soxhlet durante 10 h e posterior evaporação do solvente, de acordo com o método 31.4.02, da AOAC [1];

- Teor de proteínas - determinado pela técnica micro Kjeldahl, baseado em hidrólise e posterior destilação da amostra, de acordo com o método 31.1.08, da AOAC [1];

- Acidez Total Titulável - determinado de acordo com o método 942.15, da AOAC [1]; e

- Amido - determinado por digestão ácida em microondas, conforme a metodologia descrita por CEREDA et al. [4].

\section{2 - Análises microbiológicas}

Foram realizadas análises de Coliformes a $45{ }^{\circ} \mathrm{C}$, Salmonella e Bacillus cereus, segundo VANDERZANT \& SPLITTSTOESSER [17].

\section{3 - Pesquisa de sujidades}

Realizada conforme FONTES \& FONTES [7].

\section{3 - RESULTADOS E DISCUSSÃo}

\section{1 - Caracterização físico-química}

Na Tabela 1, encontram-se os resultados da caracterização físico-química das amostras de farinha de mandioca do grupo seca, subgrupo fina, tipo 1.

Com relação à umidade, todas as amostras apresentaram-se dentro dos padrões exigidos pela Portaria No 554 de 30.08.1995 da Secretaria da Agricultura, do Abastecimento e Reforma Agrária [3], que é no máximo de 13\%, estando elas na faixa de 5,48 a $7,59 \%$.

Para cinzas, a legislação exige no máximo 1,50\%, e as amostras em estudo obtiveram percentuais na faixa de 0,54 a $0,90 \%$.

Com relação à acidez total, todas as amostras apresentaram-se acima do padrão exigido pela legislação que é de $3 \mathrm{meq} \mathrm{NaOH} / 100 \mathrm{~g}$, encontrando-se na faixa de 4,11 a 7,10 meq NaOH/100 g.

Para o amido, das dez amostras analisadas, cinco apresentaram percentuais abaixo da tolerância mínima de $75 \%$ exigido pela legislação, apresentando-se na faixa de 65,67 a $74,69 \%$. As demais amostras ficaram na faixa de 75,07 a $79,59 \%$ de amido.

De acordo com a Portaria No 554 de 30.08.1995 da Secretaria da Agricultura, do Abastecimento e Reforma Agrária [3], não há referências com relação à atividade de água e aos teores de lipídios e proteínas da farinha de mandioca. Entretanto, neste estudo, foram realizadas essas determinações como complemento de informações referentes aos constituintes da farinha.

Considera-se a atividade de água igual a 0,60 como sendo o limite mínimo capaz de permitir o desenvolvimento de microrganismos, daí o fato de os alimentos desidratados, como a farinha de mandioca, serem considerados microbiologicamente estáveis. Neste trabalho, as amostras em estudo apresentaram atividade de água na faixa de 0,31 a 0,61 .

TABELA 1 - Caracterização físico-química de amostras de farinha de mandioca do grupo seca, subgrupo fina, tipo 1 .

\begin{tabular}{|c|c|c|c|c|c|c|c|}
\hline Amostra & Umidade (\%) & Atividade de água & Cinzas (\%) & Lipídios (\%) & Proteínas (\%) & $\begin{array}{l}\text { Acidez total meq } \\
\mathrm{NaOH} / 100 \mathrm{~g}\end{array}$ & Amido (\%) \\
\hline A & ${ }^{\mathrm{B}} 6,85 \pm 0,13$ & ${ }^{\mathrm{c}} 0,55 \pm 0,01$ & $\mathrm{~F} 0,54 \pm 0,03$ & ${ }^{\mathrm{BC}} 0,18 \pm 0,01$ & ${ }^{\mathrm{A}} 0,93 \pm 0,05$ & D $5,18 \pm 0,06$ & $\mathrm{~F} 72,05 \pm 0,27$ \\
\hline B & ${ }^{\mathrm{D}} 6,11 \pm 0,03$ & ${ }^{c} 0,55 \pm 0,02$ & ${ }^{\mathrm{A}} 0,88 \pm 0,00$ & ${ }^{A} 0,31 \pm 0,01$ & ${ }^{\mathrm{CD}} 0,62 \pm 0,07$ & $\mathrm{CD}_{5,34} \pm 0,04$ & $\mathrm{D} 74,69 \pm 0,29$ \\
\hline C & ${ }^{A} 7,59 \pm 0,06$ & ${ }^{\mathrm{AB}} 0,59 \pm 0,00$ & $\mathrm{~F} 0,54 \pm 0,01$ & ${ }^{\mathrm{AB}} 0,23 \pm 0,05$ & ${ }^{\mathrm{AB}} 0,79 \pm 0,10$ & ${ }^{c} 5,56 \pm 0,06$ & $\mathrm{E} 73,25 \pm 0,00$ \\
\hline $\mathrm{D}$ & ${ }^{A} 7,41 \pm 0,19$ & в $0,58 \pm 0,01$ & $\mathrm{E}_{0,61 \pm 0,02}$ & ${ }^{\mathrm{AB}} 0,28 \pm 0,02$ & ${ }^{\mathrm{D}} 0,53 \pm 0,01$ & ${ }^{\mathrm{D}} 5,25 \pm 0,06$ & ${ }^{\mathrm{G}} 67,67 \pm 0,24$ \\
\hline$E$ & ${ }^{\mathrm{D}} 5,92 \pm 0,04$ & ${ }^{c} 0,55 \pm 0,00$ & ${ }^{\mathrm{B}} 0,74 \pm 0,02$ & ${ }^{A} 0,31 \pm 0,04$ & ${ }^{\mathrm{BC}} 0,72 \pm 0,05$ & ${ }^{\mathrm{B}} 6,36 \pm 0,14$ & $\mathrm{CD} 75,13 \pm 0,00$ \\
\hline $\mathrm{F}$ & ${ }^{\mathrm{c}} 6,42 \pm 0,08$ & ${ }^{\mathrm{A}} 0,61 \pm 0,00$ & ${ }^{\mathrm{CD}} 0,66 \pm 0,01$ & ${ }^{A} 0,30 \pm 0,09$ & ${ }^{\mathrm{CD}} 0,59 \pm 0,06$ & ${ }^{\mathrm{D}} 5,27 \pm 0,10$ & $\mathrm{D} 74,63 \pm 0,29$ \\
\hline G & ${ }^{A} 7,33 \pm 0,08$ & ${ }^{E} 0,49 \pm 0,01$ & ${ }^{\mathrm{DE}} 0,63 \pm 0,02$ & ${ }^{\mathrm{AB}} 0,23 \pm 0,04$ & ${ }^{\mathrm{CD}} 0,59 \pm 0,05$ & ${ }^{A} 7,10 \pm 0,02$ & A $79,59 \pm 0,41$ \\
\hline $\mathrm{H}$ & ${ }^{\mathrm{c}} 6,42 \pm 0,09$ & $\mathrm{~F}_{0}, 41 \pm 0,01$ & ${ }^{\mathrm{BC}} 0,70 \pm 0,02$ & ${ }^{A B} C 0,21 \pm 0,03$ & ${ }^{\mathrm{CD}} 0,62 \pm 0,01$ & $F 4,40 \pm 0,09$ & $\mathrm{BC} 75,59 \pm 0,36$ \\
\hline 1 & ${ }^{\mathrm{B}} 6,73 \pm 0,07$ & ${ }^{\mathrm{D}} 0,52 \pm 0,01$ & ${ }^{\mathrm{A}} 0,90 \pm 0,03$ & ${ }^{\mathrm{AB}} 0,25 \pm 0,03$ & ${ }^{\mathrm{AB}} 0,85 \pm 0,04$ & ${ }^{\mathrm{G}} 4,11 \pm 0,09$ & ${ }^{\mathrm{B}} 76,10 \pm 0,51$ \\
\hline $\mathrm{J}$ & $E_{5,48} \pm 0,11$ & ${ }^{6} 0,31 \pm 0,01$ & ${ }^{\mathrm{BC}} 0,70 \pm 0,01$ & ${ }^{c} 0,11 \pm 0,02$ & ${ }^{\mathrm{A}} 0,89 \pm 0,02$ & $\mathrm{E}_{4,71 \pm 0,09}$ & $\mathrm{CD} 75,07 \pm 0,29$ \\
\hline
\end{tabular}

Os valores de uma mesma coluna, com a mesma letra, não diferem significativamente entre si (Teste de Tukey a 5\% de significância). 
A farinha de mandioca é um produto que apresenta baixos teores de lipídios e de proteínas. As amostras em estudo apresentaram teor de proteínas na faixa de 0,53 a 0,93\% e de lipídios na faixa de 0,11 a $0,31 \%$.

No geral, pode-se observar que há variações significativas (Teste de Tukey a $5 \%$ de significância) entre os constituintes das amostras analisadas. Algumas dessas variações são devido às características intrínsecas das raízes de mandioca, tais como cinzas, proteínas e lipídios. Já o teor de umidade, a atividade de água e a acidez total, estão relacionados com o seu processo de fabricação, o que comprova a falta de padronização do produto.

Na fabricação da farinha de mandioca do grupo seca, o correto é que o processo se inicie com a lavagem e descascamento das raízes de mandioca, seguindo, posteriormente, para a trituração, prensagem, desintegração e torração; sendo todas as etapas realizadas sem interrupções. No entanto, o que se observa nas Casas de Farinha é que o processo sofre interrupções, ocorrendo de a massa de mandioca triturada ficar exposta de um dia para o outro à temperatura ambiente, que na região norte gira em torno dos $25^{\circ} \mathrm{C}$ aos $35^{\circ} \mathrm{C}$, ocasionando, naturalmente, a sua fermentação, aumentando, portanto, a acidez do produto.

Embora ocorra variação nos teores de amido entre as variedades de mandioca, a variação do teor de amido observada nas amostras de farinha deste trabalho pode estar relacionada ao seu processo de fabricação, pois, em algumas Casas de Farinha, parte da massa triturada das raízes de mandioca é utilizada para a retirada de seu amido, retornando esta massa para o processamento, o que pode acarretar redução de amido no produto final, que é a farinha de mandioca torrada.

\section{2 - Contaminantes microbiológicos}

Na Tabela 2, encontram-se os resultados das análises microbiológicas nas farinhas de mandioca do grupo seca, subgrupo fina, tipo 1 .

TABELA 2 - Coliformes a $45{ }^{\circ} \mathrm{C}$ (NMP/g), Bacillus cereus (UFC/g) e Salmonella nas amostras de farinha de mandioca do grupo seca, subgrupo fina, tipo 1 .

\begin{tabular}{|c|c|c|c|}
\hline Amostra & $\begin{array}{c}\text { Coliformes } \\
45^{\circ} \mathrm{C}(\mathrm{NMP} / \mathrm{g})\end{array}$ & $\begin{array}{c}\text { Bacillus cereus } \\
\text { (UFC/g) }\end{array}$ & $\begin{array}{c}\text { Salmonella } \\
\text { Por } 25 \text { g }\end{array}$ \\
\hline$A$ & $<3$ & $<1 \times 10^{1}$ & Ausente \\
\hline B & $<3$ & $<1 \times 10^{1}$ & Ausente \\
\hline $\mathrm{C}$ & $<3$ & $<1 \times 10^{1}$ & Ausente \\
\hline $\mathrm{D}$ & $<3$ & $<1 \times 10^{1}$ & Ausente \\
\hline$E$ & $<3$ & $<1 \times 10^{1}$ & Ausente \\
\hline $\mathrm{F}$ & $<3$ & $<1 \times 10^{1}$ & Ausente \\
\hline G & $<3$ & $<1 \times 10^{1}$ & Ausente \\
\hline $\mathrm{H}$ & $<3$ & $<1 \times 10^{1}$ & Ausente \\
\hline 1 & $<3$ & $<1 \times 10^{1}$ & Ausente \\
\hline $\mathrm{J}$ & $<3$ & $<1 \times 10^{1}$ & Ausente \\
\hline
\end{tabular}

A presença de Coliformes é considerada como indicador de condições de higiene insatisfatórias na produção e/ou manipulação do alimento. O número elevado de Coliformes pode não significar contaminação direta com material fecal, mas sim manipulação inadequada, como higiene do manipulador, transporte e acondicionamento inadequados. Em todas as amostras, a presença de Coliformes detectada foi inferior a $3 \mathrm{NMP} / \mathrm{g}$, estando dentro do padrão exigido pela Resolução RDC n ${ }^{\circ} 12$ de 02.01.2001 da Agência Nacional de Vigilância Sanitária, que é de $10^{3} \mathrm{NMP} / \mathrm{g}$ para a farinha [14].

O Bacillus cereus é largamente distribuído na natureza, sendo o solo o seu reservatório natural. Por esta razão, contamina facilmente alimentos como vegetais, cereais e tubérculos [8]. A contaminação de alimentos por Bacillus cereus constitui, não somente uma importante causa de deterioração, mas também está associada à ocorrência de dois tipos de síndrome, devido à ingestão de alimentos contaminados com cepas patogênicas produtoras de toxinas, uma emética e outra diarréica [12, 16, 13]. A toxina do tipo emética é pré-formada no alimento, enquanto a do tipo diarréica é, muito possivelmente, produzida no trato intestinal, sendo os fatores de virulência ainda não completamente caracterizados [10, 13, 9]. No presente estudo, a presença de Bacillus cereus nas amostras de farinha de mandioca encontra-se dentro do permitido pela Resolução RDC n ${ }^{\circ} 12$ de 02.01.2001 da Agência Nacional de Vigilância Sanitária [14], que é de $10^{3} \mathrm{UFC} / \mathrm{g}$, uma vez que as mesmas apresentaram valores inferiores a $1 \times 10^{1} \mathrm{UFC} / \mathrm{g}$.

Levantamentos epidemiológicos realizados em vários países situam as bactérias do gênero Salmonellas entre os agentes patogênicos mais freqüentemente encontrados em surtos de toxinfecção de origem alimentar, tanto em países desenvolvidos, como em países em desenvolvimento [2]. As Salmonellas são amplamente distribuídas na natureza, sendo o trato intestinal do homem e de animais o principal reservatório natural. Os animais domésticos (cães, gatos, pássaros, etc.) podem ser portadores de Salmonellas, representando grande risco, principalmente para crianças [9]. Nas amostras em estudo, não foi detectada a presença de Salmonella.

\section{3 - Pesquisa de sujidades}

Na Tabela 3, encontram-se os resultados da pesquisa de sujidades das amostras de farinha de mandioca.

TABELA 3 - Pesquisa de sujidades das amostras de farinha de mandioca do grupo seca, subgrupo fina, tipo 1.

\begin{tabular}{ccccc}
\hline Amostra & Ácaros & $\begin{array}{c}\text { Material } \\
\text { estranho }\end{array}$ & $\begin{array}{c}\text { Fragmento } \\
\text { de insetos }\end{array}$ & Insetos \\
\hline A & 13 & 0 & 0 & 0 \\
B & 2 & 0 & 0 & 0 \\
C & 3 & 1 & 0 & 0 \\
D & 0 & 0 & 0 & 0 \\
E & 1 & 0 & 0 & 0 \\
F & 12 & 0 & 1 & 0 \\
G & 6 & 2 & 1 & 0 \\
H & 0 & 0 & 0 & 0 \\
I & 1 & 1 & 1 & 0 \\
J & 2 & 0 & 1 & 0 \\
\hline
\end{tabular}


De acordo com a Resolução RDC n ${ }^{\circ} 175$ de 08.01.2003 [15], os produtos alimentícios não devem apresentar matéria prejudicial à saúde humana, tais como: insetos em qualquer estágio de desenvolvimento, vivos ou mortos, inteiros ou em partes; outros animais vivos ou mortos, inteiros ou em parte; parasitos; excremento de insetos e/ou de outros animais; objetos rígidos, pontiagudos e/ou cortantes. Nas amostras em estudo, foi observada a presença de ácaros em oito amostras (nas quantidades de 1 a 13), presença de material estranho em três amostras (nas quantidades de 1 a 2) e fragmentos de insetos em 4 amostras (somente uma ocorrência em cada amostra). Somente em duas amostras não foi detectada a presença de sujidades.

\section{4 - CONCLUSÃO}

De acordo com a Portaria $n^{\circ} 554$ de 30.08.1995 da Secretaria da Agricultura, do Abastecimento e Reforma Agrária, das dez amostras de farinha de mandioca analisadas, em todas foram encontrados valores acima do padrão permitido para a acidez total, cujo valor máximo é de 3 meq. $\mathrm{NaOH} / 100$ g, e cinco amostras apresentaram-se abaixo da tolerância mínima exigida para o amido, que é de $75 \%$.

De acordo com a Resolução RDC no 12 de 02.01.2001 da Agência Nacional de Vigilância Sanitária, todas as amostras de farinha de mandioca apresentaram-se dentro dos padrões aceitáveis de contaminantes microbiológicos.

De acordo com a Resolução RDC n ${ }^{\circ} 175$ de 08.01.2003, das dez amostras de farinha de mandioca, foram encontradas oito fora dos padrões exigidos, por apresentarem sujidades.

\section{5 - REFERÊNCIAS BIBLIOGRÁFICAS}

[1] AOAC. Association of Official Analytical Chemists. Official methods of analysis of the AOAC International. $16^{\text {th }}$ ed. Arlington, 1995.

[2] AVILA, C. R.; GALlO, C. R. Pesquisa de Salmonella spp. em Leite Cru, Leite Pasteurizado Tipo C e Queijo "Minas Frescal" Comercializados no Município de Piracicaba - SP. Sci. Agric., v. 1, n. 53, p. 159-163, Jan/Abr, 1996.

[3] BRASIL. Portaria no 554 de 30 de agosto de 1995. Diário Oficial. Brasília, Secretaria da Agricultura, do Abastecimento e Reforma Agrária. 1 Set., Seção 1.

[4] CEREDA, M. P.; DAIUTO, E. R.; VILPOUX, O. Metodologia de Determinação de Amido por Digestão Ácida em Microondas. Revista ABAM, 2004. 29 p.

[5] CEREDA, M. P; VILPOUX, O. F. Farinhas e derivados. In: CEREDA, M. P; VILPOUX, O. F. Série Culturas de Tuberosas Amiláceas Latino Americanas, v. 3, p. 577-620, 2003. Fundação Cargill. São Paulo.

[6] CEREDA, M. P.; VILPOUX, O. F.; TAKAHASHI, M. Balança hidrostática como forma de avaliação do teor de massa seca e amido. In: CEREDA, M. P; VILPOUX, O. F. Série
Culturas de Tuberosas Amiláceas Latino Americanas, v. 3, p. 30-46, 2003. Fundação Cargill. São Paulo.

[7] FOnTES, E. A. F.; FONTES, P. R. Microscopia de Alimentos: Fundamentos Teóricos, Editora UFV. Viçosa 2005. $151 \mathrm{p}$.

[8] FRANCO, B. D. G. M.; LANDGRAF, M. Microbiologia dos Alimentos. São Paulo: Editora Atheneu, 1996. $182 \mathrm{p}$.

[9] GHElARDI, E.; CELANDRONI, F.; SAlvetTi, S.; BARSOTTI, C.; BAGGIANI, A.; SENESI, S. Identification and characterization of toxigenic Bacillus cereus isolates responsible for two food-poisoning outbreaks. FEMS Microbiology Letters, v. 208, n. 1, p. 129-134, 2002.

[10] GRANUM, P. E. Bacillus cereus and its toxins. J. Appl Bacteriol, v. 76, p. 61-66, 1994.

[11] LIMA, U. de A. Manual técnico de beneficiamento e industrialização da mandioca. São Paulo: Secretaria de Ciência e Tecnologia, 1982. 56 p. (Série Tecnologia Agroindustrial - Programa Adequação, 2).

[12] MCELROY, D. M.; JAYKUS, L. A.; FOEGEDING, P. M. Validation and Analysis of Modeled Predictions of Growth of Bacillus cereus Spores in Boiled Rice. J. Food Protec, v. 63, n. 2, p. 268-272, 2000.

[13] MINNAARD, J.; HUMEN, M.; PÉREZ, P. F. Effect of Bacillus cereus Exocellular Factors on Human Intestinal Epithelial Cells. J Food Protec, v. 64, n. 10, p. 1535-1541, 2001.

[14] Resolução RDC no 12, de 02 de janeiro de 2001 da Agência Nacional de Vigilância Sanitária. Disponível em: http://e-legis.bvs.br/leisref/public/showAct.php?id=144. Acesso em 28.08.2006.

[15] Resolução RDC no 175, de 08 de julho de 2003 da Agência Nacional de Vigilância Sanitária. Disponível em: http://e-legis.bvs.br/eisref/public/showAct.php?id=7957. Acesso em 28.08.2006.

[16] TSEN, H. Y.; CHEN, M. L.; HSIEH, Y. M.; SHEU, S. J.; CHEN, Y. L. Bacillus cereus Group Strains, their Hemolysin BL Activity, and their Detection in Foods Using a 16s RNA and Hemolysin BL Gene-Targeted Multiplex Polymerase Chain Reaction System. J Food Protec, v. 63, n.11, p.1496-1502, 2000.

[17] VANDERZANT, C.; SPlitTSTOESSER, D. F. Compendium of methods for the microbiological examination of foods. 3. ed. Washington: American Public Health Association, 1996. $873 \mathrm{p}$.

\section{6 - AGRADECIMENTOS}

Ao Fundo Estadual de Ciência e Tecnologia (FUNTEC)/ Secretaria Executiva de Ciência, Tecnologia e Meio Ambiente (SECTAM), pelo apoio financeiro.

À Dra. Eloísa Cardoso e aos Assistentes de Pesquisa Solange Branches e Edson Sampaio, da Embrapa Amazônia Oriental, pela ajuda e apoio em todos os momentos desta pesquisa. 